\title{
Transtornos mentais, qualidade de vida e identidade em homossexuais na maturidade e velhice
}

\author{
Mental disorders, quality of life and identity in middle-age and older homosexual adults \\ Alex de Toledo Ceará1, Paulo Dalgalarrondo² \\ 1 Psicólogo, mestre em Ciências Médicas pelo Departamento de Psicologia Médica e Psiquiatria da Faculdade de Ciências Médicas da Universidade Estadual de Campinas (FCM/Unicamp). \\ 2 Psiquiatra, professor titular do Departamento de Psicologia Médica e Psiquiatria da FCM/Unicamp.
}

Recebido: 15/7/2009 - Aceito: 29/10/2009

\begin{abstract}
Resumo
Contexto: Em nossa sociedade, sujeitos de orientação homossexual (SOHom) têm sido expostos de maneira incisiva a atitudes de discriminação e preconceito. Objetivo: Investigar as dimensões saúde mental, qualidade de vida e identidade psicossocial em homossexuais na maturidade e na velhice. Método: Os sujeitos foram captados pela estratégia "bola de neve". Foram utilizados procedimentos quantitativos e qualitativos com os instrumentos: MINI Plus, WHOQOL-bref, e entrevistas semiestruturadas por meio do inventário de identidade psicossocial. Foram entrevistados 40 SOHom (grupo de estudo), comparando-os a 40 sujeitos de orientação heterossexual (SOHet) (grupo contraste), pareados individualmente por gênero, idade, escolaridade e classe social. Resultados: Verificou-se maior frequência de transtornos mentais no grupo de estudo com 15 (37,5\%) casos, em comparação ao grupo contraste, com oito (20\%). O risco de suicídio estava presente em três (7,5\%) participantes do grupo de estudo. Dos sujeitos no grupo de estudo com algum transtorno mental, 11 (73,3\%) não revelavam a orientação homossexual em áreas significativas de sua vida $(\mathrm{p}=0,00001)$. Os sujeitos homossexuais apresentaram melhor qualidade de vida no domínio social em comparação aos heterossexuais. Conclusão: Os sujeitos homossexuais desta pesquisa revelaram, na maturidade e na velhice, maior frequência de transtornos mentais, porém melhor qualidade de vida. É possível que a homofobia internalizada possa estar associada a dificuldades psicossociais. Sendo assim, pode-se sugerir que a não revelação da homossexualidade e o esforço no curso da vida em ocultá-la talvez representem fatores associados à maior ocorrência de transtornos mentais.
\end{abstract}

Ceará AT, Dalgalarrondo P / Rev Psiq Clín. 2010;37(3):118-23

Palavras-chave: Homossexualidade, velhice, transtornos mentais, identidade, qualidade de vida.

\begin{abstract}
Background: In our society subjects with homosexual orientation have been strongly exposed to attitudes of discrimination and prejudice. Objective: To investigate the mental health, life quality and psychosocial identity dimensions in subjects with homosexual orientation in the maturity and old age. Method: The subjects were identified by using the snowball strategy quantitative and qualitative methods were utilized with the following tools: MINI Plus, WHOQOL-bref, and semi structured interviews through psychosocial identity inventory. Forty subjects with homosexual orientation (study group) were interviewed, comparing them to 40 subjects with heterosexual orientation (contrast group), in pairs of individuals by gender, age, education and social class. Results: A larger frequency of mental disruption was verified in the study group, 15 (37,5\%) cases, in comparison to the contrast group, eight (20\%) cases. The risk of suicide was present in three $(7,5 \%)$ individuals of the study group. Of the individuals who presented some mental disruption in the study group, 11 (73,3\%) did not reveal the homosexual orientation in significant social areas of their lives $(\mathrm{p}=0,00001)$. The subjects with homosexual orientation presented better life quality in the social domain in comparison to the subjects with heterosexual orientation. Discussion: The homosexual subjects of this research in the maturity and old age showed more frequency of mental disruption, although a better life quality. It is possible that internalized homophobia may be associated with psychosocial difficulties. Thus, the study may suggest that the act of not revealing the homosexuality and the effort across the life course to hide it has strong association with the presence of mental disruption.
\end{abstract}

Ceará AT, Dalgalarrondo P / Rev Psiq Clín. 2010;37(3):118-23

Keywords: Homosexuality, old age, mental disorders, identity, life quality.

\section{Introdução}

A orientação homossexual refere-se à preferência sexual por indivíduos do mesmo sexo biológico, compreendendo aspectos como a atração sexual, comportamentos, fantasias e preferências emocionais ou sociais' 1 .

A orientação sexual é considerada como parte da identidade individual que é composta por dimensões tais como: sexo biológico, identidade de gênero, papel social e orientação do desejo sexual ${ }^{1}$.

O enrijecimento social e individual da aceitação da homossexualidade ou da diversidade das orientações sexuais pode dificultar a aceitação da própria identidade, associado a pior ajustamento social, baixa autoaceitação, baixa autoestima e autodepreciação²

Segundo Friend ${ }^{3}$, o discurso social recriminatório da homossexualidade foi mais presente e impactante no passado e vem diminuindo nos últimos anos. Ele atinge incisivamente as gerações que constituem os idosos atuais, que internalizaram conceitos negativos a respeito da diversidade das orientações sexuais. Segundo esse autor, a internalização dessas ideologias pelos sujeitos homossexuais estabelece uma condição potencialmente conflitante, dificultando a autoaceitação e proporcionando uma baixa autoestima, aliada a uma limitada qualidade de vida.

Indivíduos que foram expostos a eventos estressantes, como a discriminação em virtude de sua orientação homossexual, estão mais sujeitos a desenvolver um certo isolamento psicológico e social ${ }^{2}$.

O suporte social existente na velhice é um fator importante para a qualidade de vida ${ }^{4}$. Nesse sentido, a ausência de suportes sociais favoráveis, em um contexto hostil e preconceituoso à orientação homossexual, pode contribuir para o sofrimento mental e mesmo para o aumento do risco de suicídio .

Em nossa sociedade, são frequentes concepções homofóbicas que alicerçam práticas discriminatórias e preconceituosas ${ }^{6}$. 
De modo geral, no Brasil não há estudos conduzidos de forma sistemática sobre saúde mental, qualidade de vida e identidade em idosos com orientação homossexual. Este estudo visa preencher, pelo menos em parte, essa lacuna no conhecimento científico.

\section{Método}

\section{Critérios de inclusão e exclusão}

Foram entrevistados os sujeitos que se autodefiniram claramente como homossexuais (ou heterossexuais no grupo contraste), condição essa confirmada mediante as entrevistas realizadas por intermédio do inventário de identidade psicossocial. Os sujeitos eram pertencentes à faixa etária da quinta década de vida em diante e aceitaram de livre escolha serem entrevistados.

Não foram entrevistados sujeitos que apresentassem déficit cognitivo, quadro demencial ou retardo mental, ou dúvidas significativas em relação à sua orientação sexual.

\section{Captação dos sujeitos}

Foi utilizado o sistema de "bola de neve", ou seja, foi pedido aos sujeitos entrevistados que indicassem outros sujeitos de seu meio sociocultural.

Trata-se de método não randômico, portanto sujeito a vieses de seleção de indivíduos mais dispostos a participar de uma pesquisa.

\section{Amostra}

Entre janeiro de 2007 a junho de 2008, foram entrevistados 40 sujeitos $(\mathrm{n}=40)$ de orientação homossexual, 20 do gênero feminino e 20 do gênero masculino, e 40 sujeitos com orientação heterossexual pareados por idade, gênero, nível de escolaridade e classe social. Os sujeitos deveriam ter pelo menos 50 anos de idade. Todas as entrevistas foram realizadas uma a uma pelo primeiro autor (ATC) da pesquisa.

\section{Instrumentos}

Os instrumentos quantitativos padronizados aplicados foram WHOQOL-bref para qualidade de vida e o MINI International Neuropsychiatric Interview (MINI Plus 5.0.0) para saúde mental. Este instrumento consiste em uma entrevista diagnóstica estruturada que investiga os transtornos mentais do eixo I do DSM-IV-R e da CID-10.

A metodologia qualitativa utilizou-se de entrevistas semiestruturadas, com um inventário de identidade psicossocial com questões apenas para os sujeitos homossexuais. Somente as questões desse inventário relacionadas ao processo de envelhecimento foram utilizadas também nas entrevistas com os heterossexuais.

\section{Procedimentos}

As respostas obtidas pelos instrumentos quantitativos geraram dados estatísticos categoriais e contínuos, os quais foram analisados utilizando-se os testes estatísticos de McNemar, Wilcoxon, Qui-quadrado, Fisher e Mann-Whitney. O nível de significância considerado foi de $\mathrm{p}<0,05$.

\section{Análise dos dados}

$\mathrm{Na}$ análise dos dados qualitativos, foram utilizados métodos de interpretação mediante a técnica de análise temática de conteúdo de acordo com Minayo ${ }^{7}$.

As questões do inventário de identidade psicossocial referentes a vergonha, orgulho e revelação da homossexualidade foram fechadas. Essas questões geraram variáveis categóricas ( sim ou não) quanto ao sentimento de vergonha da orientação e (parcial ou total) quanto à revelação da orientação sexual à sociedade. Tais variáveis categóricas foram cruzadas com as variáveis quantitativas relativas à saúde mental e à qualidade de vida.

\section{Aspectos éticos}

A presente pesquisa foi submetida e aprovada pelo Comitê de Ética em Pesquisa da Faculdade de Ciências Médicas da Universidade Estadual de Campinas (FCM/Unicamp). Todos os sujeitos entrevistados foram detalhadamente informados sobre o tema e os objetivos da pesquisa.

\section{Resultados}

Na tabela 1 são apresentados os dados sociodemográficos do grupo de estudo e do grupo contraste. Por se tratar de dois grupos pareados, não houve diferenças quanto a idade, gênero e escolaridade entre ambos.

Tabela 1. Dados sociodemográficos

\begin{tabular}{|c|c|c|c|c|}
\hline Variáveis & Categorias & $\begin{array}{l}\text { Grupo de } \\
\text { estudo }\end{array}$ & $\begin{array}{c}\text { Grupo } \\
\text { contraste }\end{array}$ & $\begin{array}{l}\text { Valor } \\
\text { de } p\end{array}$ \\
\hline Idade & $\begin{array}{l}\text { Média } \\
\text { Máxima } \\
\text { Mínima }\end{array}$ & $\begin{array}{c}58,6 \pm 4,04 \\
76 \\
54 \\
\end{array}$ & $\begin{array}{c}59,3 \pm 3,99 \\
74 \\
55 \\
\end{array}$ & \\
\hline Gênero & $\begin{array}{l}\text { Masculino } \\
\text { Feminino }\end{array}$ & $\begin{array}{l}20(50 \%) \\
20(50 \%)\end{array}$ & $\begin{array}{l}20(50 \%) \\
20(50 \%)\end{array}$ & \\
\hline Escolaridade & $\begin{array}{c}\text { Fundamental } \\
\text { Médio } \\
\text { Superior }\end{array}$ & $\begin{array}{c}6(15 \%) \\
18(45 \%) \\
16(40 \%) \\
\end{array}$ & $\begin{array}{c}6(15 \%) \\
18(45 \%) \\
16(40 \%) \\
\end{array}$ & \\
\hline Renda & $\begin{array}{l}\text { Média } \\
\text { Máxima } \\
\text { Mínima }\end{array}$ & $\begin{array}{c}2.115,00 \\
10.000,00 \\
700,00 \\
\end{array}$ & $\begin{array}{c}2.157,00 \\
14.000,00 \\
600,00 \\
\end{array}$ & 0,5829 \\
\hline Etnia & $\begin{array}{c}\text { Branca } \\
\text { Negra } \\
\text { Parda } \\
\text { Oriental }\end{array}$ & $\begin{array}{c}33(82,5 \%) \\
1(2,5 \%) \\
3(7,5 \%) \\
3(7,5 \%)\end{array}$ & $\begin{array}{c}33(82,5 \%) \\
1(2,5 \%) \\
5(12,5 \%) \\
1(2,5 \%)\end{array}$ & 0,3437 \\
\hline Estado civil & $\begin{array}{l}\text { Solteiros } \\
\text { Separados } \\
\text { Casados } \\
\text { Viúvos }\end{array}$ & $\begin{array}{c}38(95 \%) \\
2(5 \%)\end{array}$ & $\begin{array}{c}3(7,5 \%) \\
5(12,5 \%) \\
22(55 \%) \\
10(25 \%)\end{array}$ & \\
\hline Tem filhos & $\begin{array}{l}\text { Sim } \\
\text { Não }\end{array}$ & $\begin{array}{c}5(12,5 \%) \\
35(87,5 \%)\end{array}$ & $\begin{array}{c}31(77,5 \%) \\
9(22,5 \%)\end{array}$ & 0,0001 \\
\hline $\begin{array}{l}\text { Frequência de } \\
\text { convívio familiar }\end{array}$ & $\begin{array}{l}\text { Alta } \\
\text { Média } \\
\text { Baixa }\end{array}$ & $\begin{array}{c}19(47,5 \%) \\
5(12,5 \%) \\
16(40 \%) \\
\end{array}$ & $\begin{array}{c}23(57,5 \%) \\
5(12,5 \%) \\
12(30 \%) \\
\end{array}$ & 0,7169 \\
\hline $\begin{array}{l}\text { Frequência de } \\
\text { convívio com a mesma } \\
\text { faixa etária }\end{array}$ & $\begin{array}{l}\text { Alta } \\
\text { Média } \\
\text { Baixa }\end{array}$ & $\begin{array}{c}30(75 \%) \\
4(10 \%) \\
6(15 \%) \\
\end{array}$ & $\begin{array}{c}24(60 \%) \\
3(7,5 \%) \\
13(32,5 \%) \\
\end{array}$ & 0,3916 \\
\hline Aposentados & $\begin{array}{l}\text { Sim } \\
\text { Não }\end{array}$ & $\begin{array}{l}22(55 \%) \\
18(45 \%) \\
\end{array}$ & $\begin{array}{l}27(67,5 \%) \\
13(32,5 \%) \\
\end{array}$ & 0,3323 \\
\hline
\end{tabular}

\section{Saúde mental}

Quanto à prevalência de transtornos mentais entre o grupo de estudo (sujeitos de orientação homossexual - SOHom) e o grupo contraste (sujeitos de orientação heterossexual - SOHet), não existiram diferenças estatisticamente significativas. No grupo de estudo, 15 (37,5\%) sujeitos apresentaram algum transtorno mental e $25(62,5 \%)$ sujeitos não apresentaram. No grupo de heterossexuais, oito (20\%) sujeitos apresentaram algum transtorno mental contra 32 (80\%) que não apresentaram $(\mathrm{p}=0,1671)$.

Os transtornos mentais mais presentes foram o transtorno depressivo maior, com seis (15\%) casos no grupo de estudo e quatro (10\%) no grupo contraste, e o transtorno de ansiedade generalizada, com cinco $(12,5 \%)$ casos no grupo de estudo e dois (5\%) casos no grupo contraste. No grupo de estudo, identificaram-se três $(7,5 \%)$ 
sujeitos com "risco de suicídio", e nenhum no grupo contraste, e um $(2,5 \%)$ sujeito nas categorias transtorno distímico, agorafobia, transtorno obsessivo-compulsivo no grupo de estudo, e nenhum no grupo contraste, um $(2,5 \%)$ sujeito com abuso e dependência de álcool no grupo de estudo e no grupo contraste, e um (2,5\%) sujeito com abuso e dependência de álcool a vida inteira no grupo contraste e nenhum no grupo de estudo.

Quanto à procura por tratamentos em saúde mental, nota-se que a busca por serviços em psicoterapia foi significativamente maior entre os SOHom do que entre os SOHet, em que 12 sujeitos do grupo de estudo SOHom buscaram psicoterapia como forma de ajuda contra quatro sujeitos no grupo contraste SOHet $(\mathrm{p}=0,0386)$.

A respeito da busca por serviços psiquiátricos, não houve diferenças significativas entre os dois grupos. Observa-se que cinco sujeitos do grupo de estudo (SOHom) buscaram tratamento psiquiátrico como forma de ajuda contra seis sujeitos no grupo contraste (SOHet).

\section{Saúde mental e vergonha da orientação (apenas SOHom)}

No grupo de SOHom, a relação entre ter experienciado sentimentos de vergonha diante da sua orientação sexual e apresentar algum transtorno mental foi estatisticamente significativa.

Dessa forma, dos 15 sujeitos que tinham algum transtorno mental, 13 (32,5\%) já vivenciaram sentimentos de vergonha diante da sua orientação sexual. Apenas dois (5\%) dos que apresentaram algum transtorno mental nunca tiveram vergonha da sua orientação. Dos 25 sujeitos que não apresentaram algum transtorno mental, 11 (27,5\%) deles já experienciaram vergonha da orientação e 14 (35\%) nunca a experienciaram $(\mathrm{p}=0,0077)$.

\section{Saúde mental e revelação da orientação (apenas SOHom)}

A relação entre revelação da homossexualidade e saúde mental demonstra que, dos 15 sujeitos que tinham algum transtorno mental, $11(27,5 \%)$ não revelavam sua homossexualidade em todas as áreas sociais de sua vida e quatro (10\%) deles revelavam sua orientação totalmente. Dos 25 sujeitos que não apresentaram algum transtorno mental, dois (5\%) não revelavam sua orientação homossexual e 23 $(57,5 \%)$ revelavam sua orientação em todas as áreas sociais da vida $(\mathrm{p}=0,00001)$

\section{Qualidade de vida}

A análise da qualidade de vida entre os SOHom e os SOHet, avaliando-se os domínios geral, físico, psicológico e ambiental, é apresentada na tabela 2. Nota-se que não houve diferenças quanto à qualidade de vida entre os grupos, exceto no domínio social, no qual os SOHom apresentaram melhor qualidade de vida.

Tabela 2. Análise da qualidade de vida entre o grupo de estudo (SOHom) e o grupo contraste (SOHet)

\begin{tabular}{|c|c|c|c|c|}
\hline & & $\begin{array}{c}\text { Grupo de } \\
\text { estudo } \\
(\mathrm{N}=40)\end{array}$ & $\begin{array}{c}\text { Grupo } \\
\text { contraste } \\
(\mathrm{N}=40)\end{array}$ & Valor de $p$ \\
\hline \multirow[t]{2}{*}{ Domínio geral } & Média & 14,80 & 14,30 & \multirow{2}{*}{0,3769} \\
\hline & Desvio-padrão & 2,67 & 2,38 & \\
\hline \multirow[t]{2}{*}{ Domínio físico } & Média & 55,00 & 53,93 & \multirow{2}{*}{0,5617} \\
\hline & Desvio-padrão & 7,22 & 8,59 & \\
\hline \multirow[t]{2}{*}{ Domínio psicológico } & Média & 65,52 & 64,27 & \multirow{2}{*}{0,6412} \\
\hline & Desvio-padrão & 8,12 & 9,43 & \\
\hline \multirow[t]{2}{*}{ Domínio social } & Média & 67,71 & 59,38 & \multirow{2}{*}{0,0038} \\
\hline & Desvio-padrão & 15,24 & 16,03 & \\
\hline \multirow[t]{2}{*}{ Domínio ambiental } & Média & 61,64 & 59,22 & \multirow{2}{*}{0,2832} \\
\hline & Desvio-padrão & 12,01 & 14,29 & \\
\hline
\end{tabular}

A análise da qualidade de vida e sua relação com ter experienciado sentimentos de vergonha diante da orientação homossexual é apresentada na tabela 3. Os sujeitos que sentiam vergonha da sua orientação homossexual apresentaram piores níveis de qualidade de vida na maioria dos domínios, quando comparados a sujeitos que não sentiam vergonha da orientação homossexual.

Tabela 3. Relação entre qualidade de vida e vergonha diante da orientação homossexual

\begin{tabular}{|c|c|c|c|c|}
\hline & & $\begin{array}{c}\text { Casos } \\
\text { negativos } \\
\text { para } \\
\text { vergonha } \\
\mathrm{N}=16(40 \%)\end{array}$ & $\begin{array}{c}\text { Casos } \\
\text { positivos } \\
\text { para } \\
\text { vergonha } \\
\mathrm{N}=24(60 \%)\end{array}$ & $\begin{array}{l}\text { Valor } \\
\text { de } p\end{array}$ \\
\hline \multirow[t]{2}{*}{ Domínio geral } & Média & 15,38 & 14,42 & \multirow{2}{*}{0,3541} \\
\hline & Desvio-padrão & 2,50 & 2,76 & \\
\hline \multirow[t]{2}{*}{ Domínio físico } & Média & 77,23 & 75,30 & \multirow{2}{*}{0,4855} \\
\hline & Desvio-padrão & 15,91 & 12,68 & \\
\hline \multirow[t]{2}{*}{ Domínio psicológico } & Média & 83,07 & 75,00 & \multirow{2}{*}{0,0624} \\
\hline & Desvio-padrão & 8,67 & 13,52 & \\
\hline \multirow[t]{2}{*}{ Domínio social } & Média & 68,75 & 67,01 & \multirow{2}{*}{0,7780} \\
\hline & Desvio-padrão & 14,75 & 15,83 & \\
\hline \multirow[t]{2}{*}{ Domínio ambiental } & Média & 61,72 & 61,59 & \multirow{2}{*}{0,8787} \\
\hline & Desvio-padrão & 8,65 & 13,99 & \\
\hline
\end{tabular}

A análise da qualidade de vida nos SOHom, averiguando-se sua relação com a revelação total ou parcial da homossexualidade, é apresentada na tabela 4 . Os sujeitos que revelavam apenas parcialmente a homossexualidade apresentaram pior qualidade de vida no domínio geral e físico do que aqueles que revelavam a homossexualidade totalmente, em todas as áreas sociais de sua vida.

Tabela 4. Relação entre qualidade de vida e revelação da homossexualidade, de maneira total ou parcial

\begin{tabular}{|c|c|c|c|c|}
\hline & & $\begin{array}{c}\text { Revelação } \\
\text { total } \\
\mathrm{N}=27(67,5 \%)\end{array}$ & $\begin{array}{c}\begin{array}{c}\text { Revelação } \\
\text { parcial } \\
\mathrm{N}=13(32,5 \%)\end{array} \\
\end{array}$ & $\begin{array}{l}\text { Valor } \\
\text { de } p\end{array}$ \\
\hline \multirow[t]{2}{*}{ Domínio geral } & Média & 15,70 & 12,92 & \multirow{2}{*}{0,0038} \\
\hline & Desvio-padrão & 2,27 & 2,53 & \\
\hline \multirow[t]{2}{*}{ Domínio físico } & Média & 79,50 & 68,96 & \multirow{2}{*}{0,0083} \\
\hline & Desvio-padrão & 10,56 & 17,46 & \\
\hline \multirow[t]{2}{*}{ Domínio psicológico } & Média & 80,71 & 73,08 & \multirow{2}{*}{0,1671} \\
\hline & Desvio-padrão & 9,54 & 16,01 & \\
\hline \multirow[t]{2}{*}{ Domínio social } & Média & 68,83 & 65,38 & \multirow{2}{*}{0,5261} \\
\hline & Desvio-padrão & 14,73 & 16,61 & \\
\hline \multirow[t]{2}{*}{ Domínio ambiental } & Média & 62,62 & 59,62 & \multirow{2}{*}{0,3309} \\
\hline & Desvio-padrão & 11,87 & 12,53 & \\
\hline
\end{tabular}

\section{Resultados qualitativos}

\section{Identidade psicossocial}

Nos relatos obtidos por meio do inventário de identidade psicossocial (apenas para SOHom), foram identificadas as temáticas que se referem aos temas abaixo descritos:

\section{Revelação parcial da homossexualidade}

"Jamais revelaria. É uma coisa que não dá para mim e seria uma coisa impossível na minha casa e na minha família. Eu me sinto conformado com o fato de que não falarei."

"Nunca expus está história de ser gay, exceto para minha mãe, com ela eu não tinha problemas, ela sabe. Agora, sobre o sentimento que se tem, é de que você trai a sua família. Você na verdade mostra-se uma coisa, mas é uma outra pessoa." 


\section{Revelação total da homossexualidade}

"Na certeza tive que expor que era gay. Me separei da minha mulher e enfrentei todas as dificuldades do mundo. Daí você se assume, alguns perguntam, outros não perguntam, já percebem, mas é uma onda que te alivia, você se sente assumido diante do mundo."

"Eu me sinto muito bem diante das pessoas, mas não é todo mundo que é assim, porque tem gente que não se mostra nem mesmo numa boate, fica se escondendo. Eu já encontrei uma pessoa que me conhecia, ela era de Nova Odessa e, quando nos vimos na boate, ela ia para um lado e eu ia para outro lado. Mas era ele quem fugia de mim, até que uma hora nós nos encontramos num corredor que dava acesso ao banheiro e não teve jeito, então eu falei: cara, eu não estou aqui? Se eu estou te vendo é porque eu estou aqui, do mesmo jeito que você está aqui, então não sou eu quem vai falar de você. Daí a figura ficou mais calma."

\section{Experiências de discriminação}

"Fui discriminado sem dúvidas, ao longo da vida, e isso só mudou agora. Acho que não percebo mais, ou não ligo mais, tenho maturidade e vejo que é pequeno discriminar alguém. Hoje eu lido muito melhor com o preconceito, eu não tenho dúvidas. Eu o ignoro. O preconceito não tem relevância pra mim."

"Já senti que fui discriminado direta e indiretamente. Pessoas que falaram mal de mim, falaram coisas, não me respeitaram, fazem piadas, e coisas assim, principalmente no início, quando comecei a trabalhar, e até na escola, quando eu era pequeno. Teve gente que simplesmente mudava de assunto quando eu me aproximava e acho que não tive algumas oportunidades na vida por parecer homossexual. Hoje não sei se ligaria. Também seleciono mais os meus ambientes e não fico dando a cara para bater de graça."

\section{Vergonha da orientação homossexual}

"Acho que não devemos ter vergonha nunca, em momento nenhum. Já senti vergonha, tem a ver com desconhecimento e com insegurança. Eu repudio esse sentimento hoje em dia."

"Vergonha... Fico pensando se é normal ou não ser homossexual, se as pessoas exageram quando falam e condenam, porque as pessoas são picantes, são sacanas também. Será que elas têm razão no que falam?"

"Não. Não vejo os conflitos que tive como uma questão de vergonha, e sim de falta de clareza. Não me aceitava."

\section{Orgulho da orientação homossexual}

"Tenho, porque foi difícil me aceitar, teve um caminho longo até aqui, então como poderia não ter orgulho. Eu consegui as coisas mesmo sendo gay. Sair com um homem que uma mulher queria é uma vitória. É até um orgulho bobo, mas eu tenho orgulho."

"Não, orgulho não, nem nada. É como eu sou."

"Sim, tenho orgulho, mas não vou numa passeata em São Paulo. Aquilo é como uma festa, não combina comigo." frente."

"Eu tenho orgulho de ter mandado ver, enfrentado a coisa de

"Orgulho, não sinto orgulho, se pudesse escolher, escolheria ser heterossexual”.

\section{Discussão}

Os sujeitos homossexuais idosos ou adultos maduros dessa pesquisa revelaram boa frequência de convívio familiar e de convívio com pessoas da mesma faixa etária, não se diferenciando do grupo contraste. De fato, as percepções de que os homossexuais mais velhos são solitários e socialmente isolados, mais privados do contato familiar do que os idosos heterossexuais, não foram confirmadas nessa população investigada. Esse dado alinha-se às conclusões de Kelly ${ }^{8}$ e de Berger ${ }^{9}$ quanto às afirmações de que homossexuais idosos têm bom nível de integração social.

É importante ressaltar que essa população estudada, tanto o grupo de estudo como o grupo contraste, é oriunda de uma classe social com renda média superior à da população geral, em que a maioria dos sujeitos apresentava nível de escolaridade de ensino médio ou superior. Seria oportuno investigar se esses dados relativos à interação e ao convívio social, bem como os resultados quanto à qualidade de vida e à saúde mental, seriam diferentes em uma população com baixa renda e menor nível de escolaridade.

Salienta-se como uma das limitações dessa pesquisa que a seleção dos indivíduos entrevistados não foi randômica. Dessa forma, os sujeitos da pesquisa podem ter indicado pessoas de seu círculo social com características semelhantes entre si, o que influenciaria os resultados. Também é possível que sujeitos que voluntariamente concordaram em participar dessa pesquisa apresentem melhor saúde mental e qualidade de vida que sujeitos sorteados aleatoriamente.

\section{Identidade psicossocial}

A revelação ou o encobrimento da orientação sexual mostraram-se uma variável importante nesse estudo.

Embora todos os 40 sujeitos do grupo de estudo se autodeclarassem homossexuais, condição exigida para inclusão na pesquisa, cerca de um terço deles, 13 (32,5\%), revelavam a homossexualidade apenas parcialmente, ou seja, esforçavam-se por encobri-la em áreas sociais significativas de sua vida, como família e trabalho. Todavia, ressalta-se que cerca de dois terços deles, 27 (67,5\%), isto é, a maioria, revelavam sua orientação em todas as áreas da vida social.

O processo de revelação da orientação homossexual, denominado popularmente como "sair do armário", é considerado um "turning point" da vida de gays e de lésbicas e um ponto importante no desenvolvimento da identidade homossexual ${ }^{2}$.

Os relatos referentes a esse esforço de não serem descobertos indicam, em alguns casos, um aparente acordo tácito familiar em não abordar questões relativas à orientação sexual, mantendo-a em sigilo. Alguns indivíduos afirmaram categoricamente que se sentiam incapazes de expor essa dimensão de sua vida, ou seja, a orientação homossexual, e suas vivências aos familiares e em outros ambientes sociais como o trabalho.

Em sentido oposto, alguns sujeitos afirmaram o quanto o "sair do armário" configurava-se como marcante ponto de mudança em sua vida, fosse na juventude, na vida adulta ou na maturidade. Dessa forma, viu-se ressaltado, em alguns relatos, um grande alívio interno experienciado quando se dava a exposição da orientação homossexual. Alguns até relataram experienciar o aumento da autoconfiança no enfrentamento de situações de discriminação e preconceito.

Esses aspectos observados aqui se relacionam positivamente ao que Kimmel 10 menciona ao descrever o efeito "buffer" que o "sair do armário" pode proporcionar aos homossexuais, favorecendo a capacidade de adaptação a outras situações de enfrentamento, relacionadas à homossexualidade.

Quanto aos sentimentos de vergonha diante da orientação homossexual, possíveis indicativos de homofobia internalizada ${ }^{11}$, mais da metade dos sujeitos afirmaram já ter experienciado esse sentimento, com $24(60 \%)$ casos positivos contra 16 (40\%) que alegaram nunca ter sentido vergonha da orientação.

Esses dados são corroborados por Adelman², ao afirmar que a população de SOHom de maior idade teve mais contato com ideologias heterossexistas, desenvolvendo possivelmente mais sentimentos homofóbicos como a vergonha detectada no presente estudo.

Ainda assim, notam-se sentidos diferenciados nos posicionamentos quanto à vergonha, indicando-se, em alguns momentos, sua superação na vida adulta avançada e na velhice. Nesses casos, o sentimento de vergonha da orientação sexual foi relacionado com fases anteriores da vida, como a adulta inicial e a adolescência.

Essa superação da vergonha, assim como os relatos que expressam maior capacidade de lidar com a discriminação, foi atribuída 
à maior experiência de vida, durante a qual esses sujeitos puderam desenvolver um melhor repertório de enfrentamento de situações adversas.

Pode-se notar, em algumas narrativas, certo repúdio e inconformidade com a possibilidade de sentir vergonha de sua própria orientação sexual. É possível supor que esse repúdio à vergonha refira-se ao esforço empreendido por esses sujeitos em positivar suas identidades, o que explicaria o alto número de indivíduos com sentimentos de orgulho da orientação, com 28 (70\%) afirmações nesse sentido.

Curiosamente, ainda que 28 (70\%) indivíduos tenham verbalizado sentir orgulho da orientação homossexual, ocorreram posicionamentos taxativos de não compreensão quanto ao sentido de se ter orgulho da orientação sexual. Esses sujeitos enfatizaram a simples autoaceitação como sentimento básico e necessário ao bem-estar pessoal diante da homossexualidade.

Semelhantemente, observam-se algumas expressões de não identificação com movimentos políticos e sociais de afirmação de direitos dos gays e das lésbicas no Brasil. Essas narrativas expressam críticas à parada gay, fato que talvez explique por que esses movimentos atingiram maior expressividade social somente há pouco tempo, influenciando mais fortemente coortes mais jovens. De fato, $12(30 \%)$ dos sujeitos afirmaram não ter orgulho da orientação homossexual.

\section{Qualidade de vida}

Curiosamente, apesar da homofobia presente na sociedade, os resultados apontam que a qualidade de vida dos SOHom foi melhor que a dos SOHet no domínio social $(\mathrm{p}=0,0038)$. Era esperado que, pelas experiências adversas de discriminação em que gays e lésbicas estão expostos ${ }^{12}$, houvesse piores níveis de qualidade de vida para o grupo de estudo no domínio social.

É possível, entretanto, supor que gays e lésbicas invistam mais na busca de contatos sociais com seus pares ou envolvam-se com maior intensidade socioemocional com aqueles que conheçam. Um motivo que pesaria nesse sentido, atuando como uma variável de confusão, refere-se ao perfil acentuadamente distinto quanto ao estado civil e à estrutura familiar dos dois grupos estudados. Os $\mathrm{SOHom}$, em sua grande maioria, eram solteiros e não tinham filhos, o que os levariam talvez a dar maior ênfase nos contatos sociais.

Não foram encontradas diferenças estatisticamente significativas entre esses dois grupos nos demais domínios da qualidade de vida.

É importante ressaltar que a qualidade de vida dos SOHom que necessitavam administrar uma vida gay/lésbica, oculta e distinta de uma aparente vida como heterossexual em alguns setores de sua vida, mostrou-se significativamente pior no domínio geral $(\mathrm{p}=0,0038)$ e físico ( $p=0083$ ), em comparação aos sujeitos que se revelavam totalmente como homossexuais. O domínio físico corresponde às questões relacionadas à energia para realizar atividades cotidianas da vida e pode relacionar-se a estados depressivos.

Identificou-se aqui leve tendência à pior qualidade de vida no domínio psicológico em sujeitos que sentiam vergonha da orientação $(p=0,0624)$. Nesse mesmo sentido, esses SOHom que experienciaram vergonha da orientação sexual também tiveram piores escores (embora sem alcançar nível de significância estatístico) em todos os demais domínios da qualidade de vida, isto é, domínios geral, físico, social e ambiental, quando comparados aos sujeitos que não sentiam vergonha da orientação homossexual.

\section{Saúde mental}

Quanto à prevalência de transtornos mentais, observou-se uma porcentagem maior de casos positivos entre os SOHom, com $15(37,5 \%)$ casos, do que entre os SOHet, com oito (20\%) casos.

Os transtornos mais presentes foram a depressão maior com seis (15\%) casos entre os SOHom e quatro (10\%) casos entre os SOHet, e o transtorno de ansiedade generalizada, com cinco $(12,5 \%)$ casos entre os SOHom e apenas dois (5\%) entre os SOHet. O maior número de casos positivos para transtorno mental entre os SOHom pode se referir à exposição a experiências de discriminação ${ }^{3}$, pois todos os sujeitos do grupo de estudo relataram vivências dessa natureza ao longo de sua vida.

Chama a atenção, em uma amostra com $\mathrm{N}=80$, a constatação de três casos positivos para o risco de suicídio no grupo de estudo, pois, no Brasil, a prevalência do suicídio como principal causa de morte entre indivíduos com a faixa etária de 50 a 59 anos é de $10,3 \%$, e acima de 60 anos é de $14,2 \%{ }^{13}$. Também chama a atenção que nenhum caso positivo para o risco de suicídio foi encontrado no grupo contraste.

Desses três casos, dois se tratavam de mulheres com ideações suicidas desenvolvidas a partir de frustrações na vida afetiva/sexual, e um de um homem que apresentava fortes sentimentos de solidão, isolamento e questionamentos quanto à orientação sexual.

A constatação quanto ao risco maior de suicídio entre os SOHom no presente estudo é semelhante à encontrada em outras pesquisas que investigam a saúde mental nesse mesmo grupo ${ }^{11,14,15}$.

Ambos os grupos de estudo e contraste apresentaram maior prevalência de transtornos mentais que a população idosa geral, que é de $1 \%$ a $5 \%$ para depressão maior e de 5,5\% para os transtornos de ansiedade ${ }^{16}$. Um dos motivos para a maior prevalência de transtornos mentais na população dessa pesquisa pode se referir ao número pequeno dessa amostra $(\mathrm{N}=80)$.

A maior prevalência de transtornos mentais entre os SOHom, mesmo não apresentando diferença estatisticamente significativa $(\mathrm{p}=0,1671)$, é clinicamente relevante.

Enfatiza-se, no presente estudo, que o idoso com transtorno mental sofre o risco de ser duplamente estigmatizado, à medida que percepções negativas sobre a velhice são associadas a concepções de que indivíduos com transtornos mentais são um fardo para a sociedade $^{17}$. Considerando que na sociedade brasileira fazem-se presentes percepções e atitudes de preconceito em relação à homossexualidade ${ }^{6}$, é possível supor que os SOHom idosos com transtornos mentais sofram um estigma ainda maior.

É interessante notar uma forte associação, significativa estatisticamente, entre a presença de transtornos mentais e a não revelação da orientação sexual, manifestando-a parcialmente na vida social $(\mathrm{p}=0,0001)$. De fato, dos $15(37,5 \%)$ casos positivos com algum transtorno mental entre os SOHom, 11 deles (73\%), esforçavam-se em "encobrir" a orientação homossexual em diversos setores de sua vida.

Essa forte associação sinaliza que esse esforço em não se revelar, como expressão de uma crise de identidade perante a orientação sexual, estendendo-se ao longo da vida até fases adultas mais avançadas e velhice, pode proporcionar altos níveis de estresse psicológico ${ }^{18}$.

Também foi significativa a relação entre a presença de transtornos mentais e a experimentação de sentimentos de vergonha quanto à homossexualidade $(\mathrm{p}=0,0077)$. Esse dado reforça a compreensão de que a homofobia internalizada, existente nos processos de crise diante da homossexualidade, relaciona-se positivamente com a presença de transtornos mentais ${ }^{11}$

\section{Conclusão}

Os SOHom estudados na maturidade e na velhice apresentaram melhor qualidade de vida social que os sujeitos heterossexuais da mesma faixa etária.

A maioria dos sujeitos investigados revelou boa aceitação de sua orientação homossexual.

Dessa forma, ainda que tenham vivenciado experiências de discriminação em sua vida, sinalizam uma boa capacidade de enfrentamento de tais situações na maturidade e na velhice.

Verificou-se uma tendência do grupo homossexual em apresentar mais transtornos mentais e buscar significativamente mais psicoterapias.

Um aspecto relevante foi que aqueles sujeitos que apresentaram dificuldades em revelar-se socialmente como homossexuais possivel- 
mente experienciam maior sofrimento psicológico. Assim, o assumir de forma plena a orientação e a identidade homossexual pode, de algum modo, estar associado a maior bem-estar psicossocial.

\section{Referências}

1. Shively M, De Cecco J. Components of sexual identity. J Homosex. 1977;3(1):41-8.

2. Adelman M. Stigma, gay lifestyles, and adjustment to aging: a study of later-life gay men and lesbians. J Homosex. 1991;20(3):7-32.

3. Friend R. Older lesbian and gay people: a theory of successful aging. J Homosex. 1991;20(4):99-118.

4. Vechia RD, Ruiz T, Bocchi SCM, Corrente JE. Qualidade de vida na terceira idade: um conceito subjetivo. Rev Bras Epidemiol. 2005;8(3):246-52.

5. MacColl P. Homosexuality and mental health services. Br Med J. 1994;308:550-1.

6. Mott L, Cerqueira M, Almeida C. O crime anti-homossexual no Brasil. Bahia: Ed. Grupo Gay da Bahia; 2002.

7. Minayo MCS. O desafio do conhecimento: pesquisa qualitativa em saúde. São Paulo: Editora Hucitec; 2004.

8. Kelly J. The aging male homosexual: myth and reality. Gerontologist. 1977;17:328-32.

9. Berger RM. Psychological adaptation of older homosexual male. J Homosex. 1980;5:161-75.
10. Kimmel DC. Adult development and aging: a gay perspective. J Soc Issues. 1978;34(3):113-30.

11. Ghorayeb DB. Saúde mental, aspectos identitários, qualidade de vida e religiosidade nas homossexualidades [Dissertação]. Campinas: Universidade Estadual de Campinas; 2007.

12. Paul JP, Catania J, Pollack L, Moskowitz J, Canchola J, Mills T, et al. Suicide attempts among gay and bisexual men: lifetime prevalence and antecedents. Am J Public Health. 2002;92(8):1338-45.

13. Ponce JC, Andreucetti G, Jesus MGS, Leyton V, Muñoz DR. Álcool em vítimas de suicídio em São Paulo. Rev Psiq Clín. 2008;Supl 1:13-6.

14. Jorm AF, Korten AE, Rodgers B, Jacomb PA, Christensen H. Sexual orientation and mental health: results from a community survey of young and middle-aged adults. Br J Psychiatry. 2002;180:423-7.

15. Sandfort TGM, Graaf R, Bijl RV, Schnabel P. Sexual orientation and psychiatric disorders: findings from the Netherlands Mental Health Survey and Incidence Study. Arch Gen Psychiatry. 2001;50(1):85-91.

16. Gordilho A. Depressão, ansiedade, outros distúrbios afetivos e suicídio. In: Freitas EV, Py L, Neri AL, Cançado FAX, Rocha SM. Tratado de geriatria e gerontologia. Rio de Janeiro: Guanabara Koogan; 2002.

17. Graham N, Lindesay J, Katona C, Bertolote JM, Camus V, Copeland JRM, et al. Redução da estigmatização e da discriminação das pessoas idosas com transtornos mentais: uma declaração de consenso. Rev Psiq Clín. 2007;34(1):39-49.

18. Peacock JR. Gay male adult development: some stage issues of an older cohort. J Homosex. 2000;40(2):13-29. 